\title{
OS AGENTES DO AGRONEGÓCIO E O USO DO TERRITÓRIO NO TRIÂNGULO MINEIRO/ALTO PARANAÍBA: DA MODERNA AGRICULTURA DE GRÃOS À EXPANSÃO RECENTE DA CANA DE AÇÚCAR ${ }^{1}$
}

\author{
Mirlei Fachini Vicente Pereira ${ }^{2}$
}

Resumo: Desde os anos 1970 e 1980 um conjunto de grandes grupos econômicos (em sua maioria estrangeiros) com atuação no setor de grãos (soja e milho) se instalou no Triângulo Mineiro/Alto Paranaíba, criando, com o apoio de políticas estatais, as condições de modernização e de especialização territorial produtiva, tornando a região um dos principais espaços do agronegócio moderno em Minas Gerais. Atualmente, novas demandas externas induzem a expansão recente do cultivo da cana de açúcar, com a inserção de novos agentes e significativa reconfiguração dos usos territoriais, revelando, mais uma vez, processos de concentração de recursos e uma situação de instabilidade territorial.

Palavras-Chave: Agentes territoriais; Especialização produtiva; Agricultura moderna; Triângulo Mineiro/Alto Paranaíba-MG.

\section{AGRIBUSINESS AGENTS AND USE OF THE TERRITORY IN TRIÂNGULO MINEIRO/ALTO PARANAÍBA (BRAZIL): OF THE MODERN AGRICULTURE OF GRAINS FOR THE RECENT EXPANSION OF SUGARCANE}

\begin{abstract}
Since the 1970 and 1980, a group of great companies (mostly foreign) that operate in the grain sector (soy and corn) is installed in Triangulo Mineiro/Alto Paranaíba region, and creates, with support of state policies, the conditions of modernization and territorial specialization productive, transforming the Triangulo Mineiro/Alto Paranaiba into main region of modern agribusiness, in Minas Gerais estate (Brazil). Nowadays, new external demands produce the recent expansion of sugarcane cultivation, with the insertion of new agents and substantial reconfiguration of territorial uses, indicating, again, a process of concentration of resources and a situation of territorial instability.
\end{abstract}

Key-Words: Use of the territory; Territorial agents; Productive specialization; Modern agriculture; Triângulo Mineiro/Alto Paranaíba (Brazil).

\section{INTRODUÇÃO}

Neste início de século, objetos técnicos extremamente modernos e ações políticas estrategicamente elaboradas por um seleto grupo de agentes da economia dotam o território brasileiro de um conteúdo extremamente avançado, no que diz respeito à atual produção agrícola de exportação. Os constantes aumentos da produtividade e da produção

\footnotetext{
${ }^{1} \mathrm{O}$ texto resulta de pesquisa realizada com auxílio financeiro da Fundação de Amparo à Pesquisa do Estado de Minas Gerais - FAPEMIG

${ }^{2}$ Licenciado e Bacharel em Geografia, Mestre em Geografia, Doutor em Geografia, Professor Adjunto, Instituto de Geografia, Universidade Federal de Uberlândia - E-mail: mirlei@ig.ufu.br DOI: 10.7154/RDG.2012.0023.0004
} 
de grãos no Brasil, e especialmente nas áreas originalmente cobertas pelos cerrados, atestam o conteúdo moderno adicionado nas últimas décadas ao território para viabilizar esta atividade - inovações científicas e tecnológicas, máquinas e insumos modernos, consolidação de uma logística que viabiliza o movimento e a circulação daquilo que é produzido, ou seja, uma adequação das infraestruturas técnicas e territoriais que se destinam quase que exclusivamente a tornar possível a produção agrícola moderna.

Considerando que a história recente do campo no Brasil pode em muito ser contada através dos esforços de agentes públicos e privados em dotar o território com as condições ideais de uma produção particularmente orientada para uma agricultura moderna (caracterizada pela presença intensa de técnica, ciência e informação) (CASTILLO, 2005), definimos trabalhar justamente no sentido de reconhecer agentes, infraestruturas e um conjunto de atividades produtivas no campo que caracterizam a região do Triângulo Mineiro/Alto Paranaíba como uma porção do território brasileiro que é, em última análise, comandada por interesses de agentes externos à região e mesmo ao país. Isto pode ser reconhecido nos constantes esforços de orientação para a produção de commodities agrícolas muito valorizadas no mercado.

Assim, toda a reconversão do cerrado nesta região, que hoje é um dos espaços de produção agrícola mais modernos de Minas Gerais resulta, diretamente, do interesse do Estado (que historicamente atuou na viabilização da agricultura moderna) e de um conjunto de grandes empresas nacionais e estrangeiras (principais agentes que organizam hoje a produção agrícola) e, sobretudo, de uma demanda (muitas vezes longínqua) por produtos que nas últimas décadas foram os responsáveis pela modernização do campo na região (grãos, especialmente soja e milho, e mais recentemente a cana-de-açúcar).

O equipamento do território e as ações nele empreendidas ocorrem a partir dos interesses de grandes grupos econômicos que orientam os tipos de cultivo, a instalação das redes logísticas e as lógicas dos fluxos, induzindo novas dinâmicas econômicas à região, orientando as políticas de crédito para o campo, fortalecendo de forma desigual um conjunto de cidades, tal como em outras regiões onde a agricultura moderna se instala (ELIAS, 2006; BERNARDES, 2007; FREDERICO, 2010) influenciando diretamente no trabalho da agricultura moderna, ainda que tais transformações pouco envolvam os problemas cotidianos da maioria dos que habitam a região. 
Deste modo, avaliamos os impactos territoriais destas transformações do campo no Triângulo Mineiro/Alto Paranaíba nas últimas décadas (a partir de 1990), levantando e analisando um conjunto de dados e, mesmo de forma não conclusiva, produzimos uma síntese que pretende colaborar para a compreensão das dinâmicas da produção agrícola regional moderna - particularmente a ação dos grandes grupos que organizam a produção de grãos (especialmente soja e milho, que possuem maior volume entre os grãos produzidos) e também a expansão da produção canavieira e de um conjunto de usinas do setor sucroalcooleiro, que recentemente tem aumentando seu número e volume de produção no Triângulo Mineiro/Alto Paranaíba. Assim, a intenção principal do texto é justamente reconhecer os principais agentes que orientam o uso agrícola do território e comandam os circuitos produtivos do moderno agronegócio na região, discutindo as implicações políticas de sua atuação para o conjunto da sociedade e do território.

\section{A agricultura moderna de grãos (soja e milho) e os principais agentes econômicos} que coordenam a produção

As políticas públicas de planejamento implantadas para a modernização do território brasileiro no período da ditadura militar, especialmente o Polocentro (criado em 1975 e inserido nas metas do II PND) (PESSOA, 2007) ${ }^{3}$, foram essenciais para a consolidação, nos cerrados do Brasil e particularmente no Triângulo Mineiro/Alto Paranaíba, de uma nova maneira de produzir os gêneros agropecuários. A partir dos anos 80 , os protagonistas da instrumentalização do território para a produção são cada vez mais os grandes grupos e empresas do setor que, de forma rápida, ocupam novos espaços no cerrado e tornam as atividades agropecuárias modernas e intensas em técnica e capital.

Pensando especificamente as atividades agrícolas, ainda que fortemente amparados pelo Estado em diferentes escalas, grandes grupos e empresas foram capazes de ditar especializações produtivas e também formas de racionalização da produção que, cada vez mais a partir dos anos 80 , caracterizam a região como um dos principais espaços de uma

\footnotetext{
3 “Os programas de estímulo à expansão agrícola desempenharam um papel importante na (re) organização desse espaço produtivo. Além do PoloCentro, tivemos o PCI (Programa de Crédito Integrado e Incorporação dos Cerrados), o Padap (Programa de Assentamento Dirigido e Incorporação dos Cerrados) e o Prodecer (Programa de Cooperação Nipo-Brasileira de Desenvolvimento Agrícola da Região dos Cerrados)" (PESSÔA, 2007, p.261).
} 
"agricultura científica globalizada" (SANTOS, 2000) em Minas Gerais e mesmo no Brasil (Figura 1).

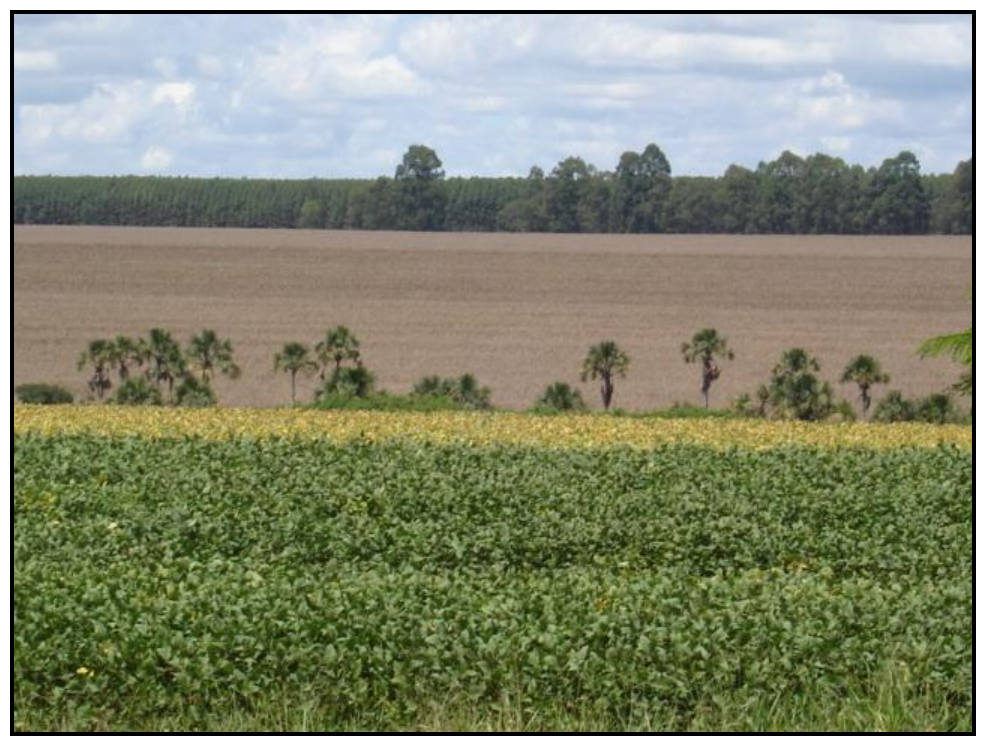

Figura 1. Área cultivada com soja, município de Indianópolis-MG.

(Foto do autor, 2010)

Reconhecendo a região como um espaço já consolidado da produção agrícola moderna (pelo menos desde os anos 70/80), com fortes vínculos à indústria e também ao comércio externo (PESSÔA, 2007), os dados que levantamos sobre a atuação de grandes grupos que organizam e coordenam a produção demonstram que o Triângulo Mineiro/Alto Paranaíba configura um espaço estratégico para grandes tradings estrangeiras e também nacionais, principalmente no que se refere a commodities hoje muito valorizadas no mercado internacional (soja, milho), mas também cada vez mais para usinas de açúcar e álcool instaladas na região que, inclusive, resultam hoje, em boa parte, de investimentos de grupos estrangeiros.

Assim, cabe salientarmos que, no que se refere ao cultivo de grãos, a moderna produção agrícola da região só ocorre pela presença de empresas que, não se envolvendo diretamente na atividade de plantio, realizam, no entanto, o trabalho de comercialização (compra e venda) e processamento do que é produzido (este é o caso das tradings Cargill, ADM, entre outros grupos), criando nexos de dependência entre produtores e agentes que comercializam a produção.

Reconhecendo a necessidade de fazermos seleções, os agentes que comandam a produção agrícola moderna no Triângulo Mineiro foram investigados a partir de um levantamento e avaliação das ações dos principais grupos do setor que atuam na região. A partir de uma 
hierarquia de importância, foram avaliados especialmente os grupos estrangeiros - Cargill, ADM e Bunge (grupos de expressão mundial, com atuação em diversas atividades e presentes em grande número de países) e uma empresa nacional - Algar Agro (Grupo Algar), que, inclusive, é de origem local, com sede em Uberlândia. Estes principais agentes comercializam e processam grande parte dos grãos produzidos no Triângulo Mineiro/Alto Paranaíba, e, deste modo, podem ser reconhecidos como os principais responsáveis pela organização da produção agrícola moderna de grãos. Vale ressaltar que outros grupos como Monsanto, Syngenta e Nidera (voltados para a produção de sementes), também possuem forte atuação no Triângulo.

O grupo Cargill, que é um dos principais agentes de organização da produção de commodities agrícolas no território brasileiro, possui na região do Triângulo Mineiro/Alto Paranaíba diferentes infraestruturas distribuídas em treze municípios, com destaque para um complexo industrial (um dos maiores do Brasil e o maior do grupo fora dos EUA) de esmagamento de soja e produção de óleo, amidos e adoçantes (funcionando em Uberlândia, desde 1986). O grupo realiza atividades de pesquisa e cultivo de sementes, compra de soja e milho, armazenamento de grãos, produção de fertilizantes (em Uberaba e Patos de Minas) e, recentemente, também tem investido na produção sucroalcooleira, com instalação de uma usina no município de Santa Vitória.

A ADM (Archer Daniels Midland Company) realiza em sete municípios da região as atividades de compra e armazenagem de grãos, processamento de soja (com planta industrial em Uberlândia, para onde converge toda a soja adquirida na região). Além da compra, armazenamento e industrialização da soja, o grupo ADM, assim como o grupo Cargill, investiu recentemente na instalação de uma usina de álcool no município de Limeira do Oeste (em parceria com o grupo nacional Cabrera).

O grupo Bunge, de origem holandesa e com atuação no Brasil desde 1905, possuía (em parceria com a Cargill) importantes atividades ligadas à produção de fertilizantes na região em estudo, trabalho este que incluía atividades de mineração, industrialização e distribuição (marca Fosfértil Fertilizantes). Recentemente, o grupo vendeu seus ativos para o grupo Vale (hoje acionista majoritário da Fosfértil/Vale Fertilizantes). Na região, atualmente o grupo Bunge direciona atualmente suas ações principalmente para a atividade sucroalcooleira.

Ainda no que se refere à produção de grãos, a Algar Agro (divisão de agronegócios do grupo Algar) atua desde a década de 70 na região do Triângulo Mineiro. Produzindo e 
comercializando grãos (sobretudo soja), a Algar Agro possui um complexo industrial no município de Uberlândia, onde realiza processamento de soja para a produção de óleo, farelos e rações animais, além de estruturas de armazenamento localizadas em outros dois municípios (Coromandel e Sacramento).

Cabe ainda salientarmos que o Triângulo Mineiro/Alto Paranaíba também constitui espaço estratégico para grupos nacionais e estrangeiros que se dedicam à pesquisa e desenvolvimento de sementes melhoradas. A Monsanto (EUA), líder mundial em biotecnologia, atua no Triângulo Mineiro/Alto Paranaíba nas atividades de pesquisa e cultivo de sementes de algodão, soja, milho e sorgo (unidades em Uberlândia e Cachoeira Dourada). Cultivando sementes em três municípios da região (Capinópolis, Perdizes e Iraí de Minas), a Monsanto localiza em Uberlândia seu centro de distribuição de sementes de milho e sorgo para a maior parte do país e também para o exterior. As infraestruturas do grupo contam com fazendas próprias e arrendadas, além de laboratórios que, recentemente, também se dedicam à pesquisa para desenvolvimento de variedades de cana de açúcar adaptadas à região (no município de Veríssimo). Ainda no que diz respeito à produção e pesquisa com sementes, a região sedia (em Uberlândia) uma unidade do grupo suíço Syngenta e também infraestruturas produtivas do grupo Nidera.

Partindo do pressuposto que as grandes empresas usam de modo seletivo o território (pois escolhem e hierarquizam os espaços mais viáveis para uma produção competitiva) (SANTOS; SILVEIRA, 2001) e conforme demonstram os dados aqui apontados, pode-se concluir que hoje a região do Triângulo Mineiro/Alto Paranaíba constitui-se como um subespaço que acolhe alguns dos principais grupos que organizam o agronegócio e comandam a produção agrícola de exportação no país, tornando-se uma região funcional (SANTOS, 1978, 1994) a esta atividade. Assim, a partir da década de 80 (quando se instalam as primeiras esmagadoras de grãos), a região conheceu um crescente incremento no volume produzido (Tabela 1), ainda que atualmente a cana de açúcar conheça um crescimento mais significativo dos que os grãos.

O município de maior destaque no setor de processamento e industrialização de grãos (complexo soja e milho) e para onde converge a maior parte dos grãos produzidos na região (mas também a produção realizada em outras partes do país) é Uberlândia. Este município sedia infraestruturas produtivas (grandes unidades de armazenamento e plantas de esmagamento/processamento e industrialização de grãos) de vários dos principais grupos do 
setor no país (Cargill, ADM, Algar Agro, entre outros de menor expressão). Articulando a produção no campo à atividade industrial, Uberlândia desempenha na região e no país uma função de centro agroindustrial (produção de amidos e adoçantes, óleo vegetal, misturas, rações e farelos) (Quadro 1).

Tabela 1. Brasil, Minas Gerais e Triângulo Mineiro/Alto Paranaíba -

Produção de milho e soja (em toneladas)

\begin{tabular}{|c|c|c|c|c|c|c|}
\hline & & 1990 & 1995 & 2000 & 2005 & 2009 \\
\hline Brasil & $\begin{array}{l}\text { Milho } \\
\text { Soja }\end{array}$ & $\begin{array}{l}11.394 .307 \\
11.487 .303 \\
\end{array}$ & $\begin{array}{l}13.946 .320 \\
11.675 .005 \\
\end{array}$ & $\begin{array}{l}11.890 .376 \\
13.656 .771 \\
\end{array}$ & $\begin{array}{l}11.549 .425 \\
22.948 .874\end{array}$ & $\begin{array}{l}13.654 .715 \\
21.750 .468 \\
\end{array}$ \\
\hline Minas Gerais & $\begin{array}{l}\text { Milho } \\
\text { Soja }\end{array}$ & $\begin{array}{l}1.410 .772 \\
558.387 \\
\end{array}$ & $\begin{array}{l}1.496 .606 \\
600.655 \\
\end{array}$ & $\begin{array}{l}1.240 .549 \\
600.054\end{array}$ & $\begin{array}{l}1.353 .544 \\
1.118 .867 \\
\end{array}$ & $\begin{array}{l}1.278 .299 \\
928.708 \\
\end{array}$ \\
\hline $\begin{array}{l}\text { Triângulo } \\
\text { Mineiro / Alto } \\
\text { Paranaíba }\end{array}$ & $\begin{array}{l}\text { Milho } \\
\text { Soja }\end{array}$ & $\begin{array}{l}327.510 \\
346.370\end{array}$ & $\begin{array}{l}368.289 \\
392.977\end{array}$ & $\begin{array}{l}337.086 \\
445.651\end{array}$ & $\begin{array}{l}371.741 \\
755.353\end{array}$ & $\begin{array}{l}377.816 \\
556.195\end{array}$ \\
\hline
\end{tabular}

Fonte: IBGE - Censos Agropecuários e Produção Agrícola Municipal (2010). Org. do autor.

\begin{tabular}{|c|c|c|c|}
\hline Grupo & Atividades & Infraestruturas & Outras informações \\
\hline $\begin{array}{l}\text { Grupo } \\
\text { Cargill } \\
\text { (comércio e } \\
\text { indústria) }\end{array}$ & $\begin{array}{l}\text { - Esmagamento e } \\
\text { processamento de } \\
\text { soja } \\
\text { - Produção de } \\
\text { Amidos, adoçantes } \\
\text { e acidulantes }\end{array}$ & $\begin{array}{l}\text { - Complexo soja (silos, } \\
\text { unidades de } \\
\text { processamento, } \\
\text { esmagadoras) } \\
\text { - Unidade de produção } \\
\text { de amido }\end{array}$ & $\begin{array}{l}\text { A unidade da Cargill em } \\
\text { Uberlândia é o maior fora dos } \\
\text { EUA. Recém ampliada, a unidade } \\
\text { aumentou em } 70 \% \text { a capacidade } \\
\text { de produção de amidos e } \\
\text { adoçantes. }\end{array}$ \\
\hline $\begin{array}{l}\text { ADM } \\
\text { (comércio e } \\
\text { indústria) }\end{array}$ & $\begin{array}{l}\text { - Processamento de } \\
\text { soja }\end{array}$ & $\begin{array}{lr}\text { - Unidade } & \text { de } \\
\text { esmagamento } & \text { e } \\
\text { secagem de soja } & \end{array}$ & $\begin{array}{l}\text { A unidade de Uberlândia é umas } \\
\text { maiores da ADM no Brasil. Toda a } \\
\text { produção de soja comercializada } \\
\text { pelo grupo na região é destinada } \\
\text { para a unidade de Uberlândia } \\
\text { para o processamento e posterior } \\
\text { exportação. }\end{array}$ \\
\hline $\begin{array}{l}\text { Algar Agro } \\
\text { (Grupo } \\
\text { Algar) } \\
\text { (comércio e } \\
\text { indústria) }\end{array}$ & $\begin{array}{l}\text { - Processamento de } \\
\text { soja } \\
\text { - Produção de óleo }\end{array}$ & $\begin{array}{l}\text { - Unidade de moagem } \\
\text { de soja } \\
\text { - Unidade de secagem } \\
\text { e esmagamento de } \\
\text { soja }\end{array}$ & $\begin{array}{l}\text { A Unidade } A B C \text { Inco. (Algar Agro) } \\
\text { de Uberlândia é um dos mais } \\
\text { avançados complexos industriais } \\
\text { de esmagamento de soja do } \\
\text { Brasil, com área de } 406 \mathrm{mil} \mathrm{m}^{2} \text {. }\end{array}$ \\
\hline
\end{tabular}

Quadro 1. Infraestruturas dos principais agentes do segmento de grãos em Uberlândia -MG Fonte: Adaptado de Coelho (2011).

Com a presença destes grandes grupos, existe, de certo modo, uma concorrência que, de fato, diferencia e define estratégias específicas de inserção e uso do território pelos agentes do agronegócio na região. A Cargill, por exemplo, que está presente no Triângulo Mineiro 
desde meados da década de 80 , detém grande parte da comercialização de soja e milho, com escritórios de compra de grãos localizados em dez municípios da região, ainda que o complexo industrial do grupo receba grãos produzidos em outras partes do país (sobretudo da região Centro-oeste). O núcleo privilegiado para as ações desta empresa é o município de Uberlândia (Figura 2).

Assim, o Triângulo Mineiro como um todo (mas especialmente nas áreas onde existe mais densa infraestrutura de transporte e armazenamento da produção) torna-se espaço privilegiado para esta agricultura moderna de commodities valorizadas no mercado, com destacada importância dos municípios de Uberaba, no que se refere ao volume da produção agrícola e do município de Uberlândia, especificamente no que diz respeito à infraestrutura de processamento da produção, tornando-se o centro polarizador e de convergência de grande parte da produção agrícola regional.

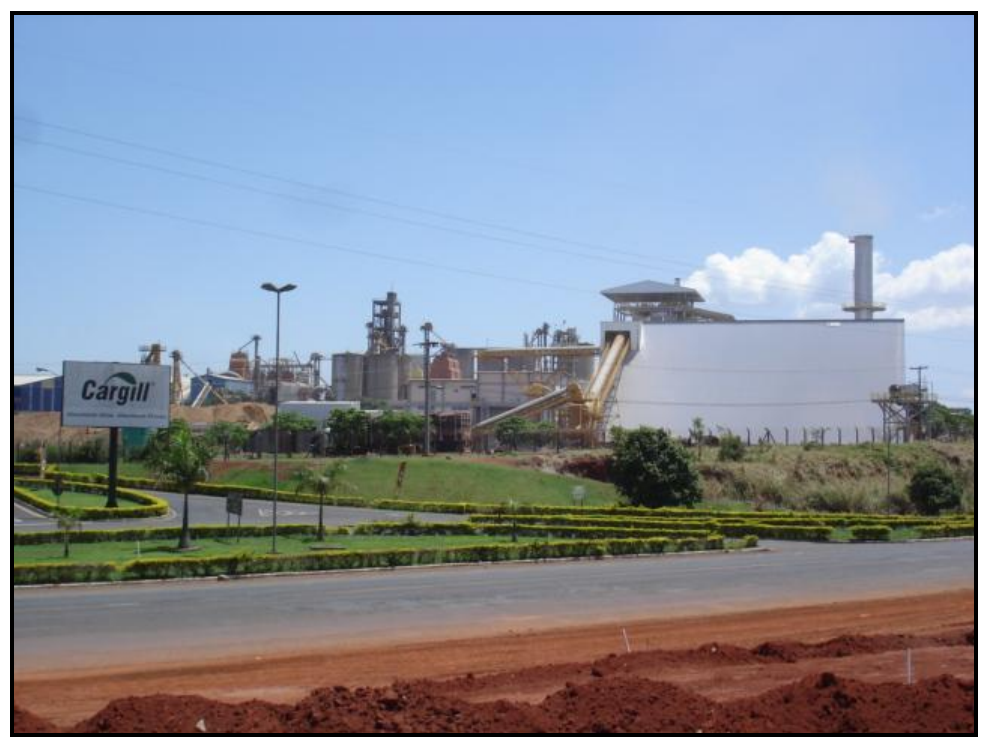

Figura 2. Complexo industrial do grupo Cargill, Uberlândia-MG (Foto do autor, 2010).

Num primeiro momento (entre os anos 1970 e 1990), se conforma uma configuração territorial favorável e um conjunto de políticas públicas que se organizaram tornaram a região propícia às práticas agrícolas baseadas nas monoculturas intensas em técnica e capital (especialmente a soja e o milho), fazendo com que o Triângulo Mineiro se tornasse um espaço muito competitivo para a atividade agrícola moderna, visto que apresenta vantagens logísticas como, por exemplo, uma rede de transportes estruturada, um importante entroncamento rodoviário que oportuniza a conexão com outras regiões, a relativa 
proximidade aos maiores centros consumidores e às infraestruturas de exportação (portos da região Sudeste), bem como aos novos espaços que constituem, nos anos 1970 e 1980, os fronts de expansão da agricultura moderna (especialmente os estados de Goiás e Mato Grosso), que a partir de então se tornaram grandes produtores de commodities agrícolas do país. Daí, o fortalecimento de um grupo local como o Algar (que recentemente expande suas atividades fora da região, com uma unidade no estado do Pará), ou ainda a escolha de Uberlândia como local estratégico para a instalação do complexo industrial da Cargill em $1985^{4}$ e mais tarde também, uma planta da ADM.

Em termos de produção agrícola propriamente dita, Uberaba é atualmente o principal município do agronegócio moderno do estado de Minas Gerais e, certamente, também um dos principais espaços da moderna produção agropecuária no país. Para além da importância indiscutível de centro especializado em genética bovina, o município também se destaca na produção de gêneros agrícolas valorizados no mercado. No ano de 2009, o município de Uberaba liderou no Estado de Minas Gerais a produção de soja (267 mil toneladas), de milho (347,9 mil toneladas) e cana-de-açúcar (4.227,5 mil toneladas). 0 município de Uberlândia, por sua vez, ocupou o quarto lugar na produção de soja do estado na safra 2009 (140,8 mil toneladas) (MINAS GERAIS, 2010).

Mas, como a natureza moderna do trabalho agrícola é dependente de nexos urbanos, grande parte dessa renda gerada pela produção moderna que se realiza no campo, acaba em grande parte tomando forma e se concentrando no urbano, onde os agentes indispensáveis ao trabalho moderno do campo se encontram localizados. Daí, mais uma vez, uma demonstração da força e da centralidade exercida pelo município de Uberlândia no conjunto do Triângulo Mineiro/Alto Paranaíba. Além do processamento industrial do que é produzido no campo e diretamente ligado ao circuito espacial de produção de grãos, o município de Uberlândia possui um conjunto de empresas que dão suporte técnico (infraestruturas de armazenamento, produção e revendas de sementes, veículos especiais e insumos), financeiro (é importante centro para a tomada de crédito) e científico (divide com Uberaba a direção executiva de um Arranjo Produtivo Local de Biotecnologia que envolve empresas voltadas para o agronegócio).

\footnotetext{
4 “Até o ano de 1985, não havia nenhuma empresa esmagadora de soja em Minas Gerais, sendo a empresa Cargill a primeira a iniciar as atividades com a produção de óleo e farelos em 1986 [planta instalada em Uberlândia], acompanhando assim o grande crescimento da produção de grãos do estado" (NEDER; CLEPS JR. (1997, p.215).
} 
Mas, se o município de Uberlândia concentra os serviços indispensáveis ao campo moderno e as plantas industriais responsáveis por boa parte do processamento dos grãos produzidos (Cargill, ADM, Algar Agro) e se o Triângulo Mineiro/Alto Paranaíba, pelo menos desde os anos 80, toma a forma daquilo que Castillo $(2007$, p.36) denomina "região competitiva" para a produção de grãos, expressando o poder que grupos hegemônicos do setor possuem em instrumentalizar o território conforme seus próprios desígnios, a partir dos anos 90, e tendo novamente como motor do processo estímulos externos, a região passa a tornar-se muito competitiva também para a produção sucroalcooleira (principalmente o etanol). Estamos, assim, diante de um processo recente de expansão de uma cultura que, de algum modo, passa a concorrer com o cultivo de grãos, inclusive com reorientação de capitais dos principais grupos que, na região, há décadas atuam no segmento de soja e milho.

\section{A expansão recente do cultivo da cana de açúcar e os seus agentes produtivos}

Reproduzindo o aumento da produção que ocorre no conjunto do território brasileiro, o Triângulo Mineiro/Alto Paranaíba se consolidou como a principal região produtora de açúcar e álcool no Estado de Minas Gerais e conhece recentemente um aumento bastante significativo no volume produzido. Dados recentes do IBGE apontam forte crescimento da produção de cana de açúcar no Estado de Minas Gerais, especialmente no Triângulo Mineiro/Alto Paranaíba na primeira década do século atual (Tabela 2), que alcançou, no ano de 2009, uma produção de mais de 41 milhões de toneladas na região, volume este que representa cerca de $70 \%$ do total da cana de açúcar produzida em todo o Estado de Minas Gerais. Uberaba se destaca como o maior município produtor do estado $(4.370,0$ mil toneladas).

As atividades do setor sucroalcooleiro presentes na região envolvem um trabalho diretamente coordenado pelas usinas para a efetivação do plantio (sobretudo por arrendamento de terras), que neste caso, também cria elos de dependência entre proprietários de terras e usinas. Diferente do que ocorre com a agroindústria processadora de grãos, a produção industrial sucroalcooleira é distribuída em diferentes municípios, haja vista a necessidade de rápido processamento pós-colheita e também pelo volume crescente da produção que é hoje realizada na região. 
Mais uma vez, é preciso compreender a dinâmica do território brasileiro e da sua participação numa divisão do trabalho definida em outras escalas (do país ou mesmo do exterior), que oferecem as pistas para a compreensão das dinâmicas locais, ou seja, as implicações territoriais que, no Triângulo Mineiro, ocorrem como resultado de uma parcela específica de trabalho que esta região desempenha no conjunto do território nacional e mesmo para fora dele.

Tabela 2. Brasil, Minas Gerais e Triângulo Mineiro/Alto Paranaíba -

Produção de cana de açúcar (em toneladas)

\begin{tabular}{l|l|l|l|l|l}
\hline & 1990 & 1995 & 2000 & 2005 & 2009 \\
\hline Brasil & & & & & \\
& 262.674 .150 & 303.699 .497 & 326.121 .011 & 422.956 .646 & 691.606 .147 \\
\hline $\begin{array}{l}\text { Minas Gerais } \\
\text { Triângulo }\end{array}$ & 17.533 .368 & 16.726 .400 & 18.706 .313 & 25.386 .038 & 58.384 .105 \\
$\begin{array}{l}\text { Mineiro / Alto } \\
\text { Paranaíba }\end{array}$ & 7.332 .891 & 6.856 .624 & 10.076 .488 & 14.459 .650 & 41.089 .128 \\
\hline
\end{tabular}

Fonte: IBGE - Censos Agropecuários e Produção Agrícola Municipal (2010). Org. do autor.

A partir dos anos 1990, mas sobretudo nos últimos anos, quando o Brasil passou a ter claras pretensões de tornar-se o principal produtor/fornecedor mundial de etanol (álcool combustível) produzido a partir da cana-de-açúcar, os espaços produtivos desta atividade ganharam novos contornos no território brasileiro, atingindo de forma significativa o Triângulo Mineiro/Alto Paranaíba.

O estado de São Paulo continua sendo o principal produtor, de modo que sua produção dobrou entre 2001/2008 e alcançou quase 300 milhões de toneladas (mais da metade da produção nacional) (PEREIRA, 2010). Como a produção da cana de açúcar é exigente em termos de área cultivada (pois é preciso grandes extensões cultivadas para garantir o volume processado anualmente pelas usinas), o Triângulo Mineiro aparece como um espaço privilegiado para a expansão dos cultivos, recebendo na primeira década do século atual um novo conjunto de agentes e infraestruturas (grandes usinas) que aumentam consideravelmente a produção na região.

A partir de levantamentos por nós realizados, até o final de 2010, eram vinte e uma as usinas de álcool e açúcar em funcionamento, instaladas em dezoito municípios no Triângulo 
Mineiro/Alto Paranaíba ${ }^{5}$ (Figura 3). A maior parte delas (doze usinas) iniciaram suas atividades entre os anos de 2001 e 2010. Os projetos de implantação de novas usinas na região (também até o final de 2010) totalizavam outros dezesseis empreendimentos (Figura 4).

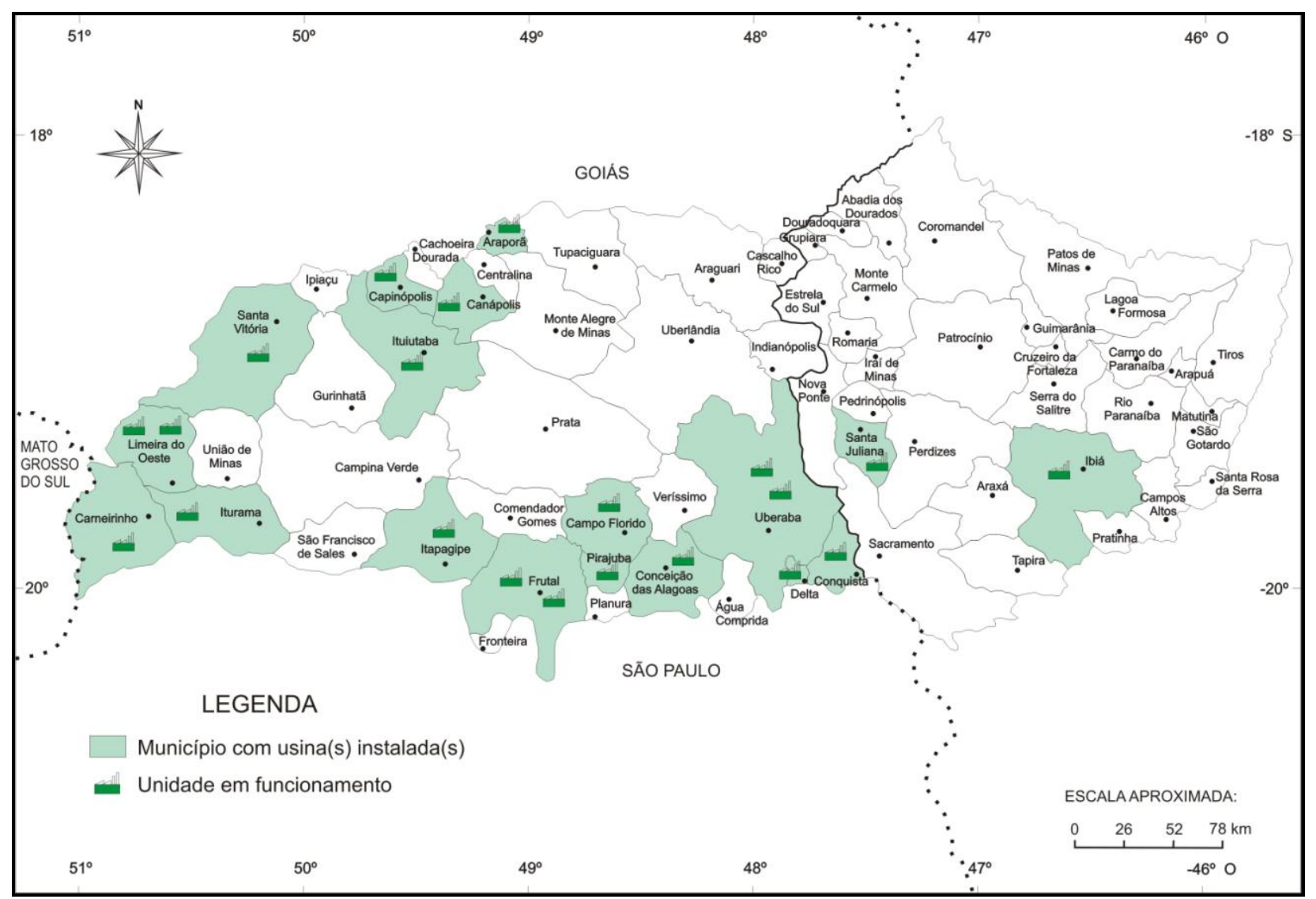

Figura 3. Usinas de açúcar/álcool em funcionamento no Triângulo Mineiro/Alto Paranaíba (2010) Fonte: SIAMIG/SINDAÇÚCAR, 2010. Sítio dos grupos na internet. Org. do autor.

Resultando de investimentos realizados por grupos externos à região (especialmente de São Paulo e também da região Nordeste), um dado novo é sem dúvida a participação expressiva também de grupos estrangeiros. Assim, capitais de grandes grupos do agronegócio são mobilizados para a implantação de novas usinas, como é o caso dos grupos Cargill, ADM, Louis Deyfrus Commodities e Bunge.

Ainda que iniciada a partir de experiências já bastante antigas de produção (como é o caso da usina de açúcar de Conquista, em funcionamento desde 1904), a região foi inserida definitivamente na produção de álcool combustível a partir das políticas de valorização do setor (Pró-alcool, nos anos 1970 e 1980). Deste modo, e até o final dos anos 1990, pelo

\footnotetext{
${ }^{5}$ As informações aqui reunidas sobre localização e funcionamento foram coletadas principalmente a partir dos dados disponibilizados pelos sindicatos do setor (Siamig/Sindaçúcar), dados estes que foram atualizados a partir de informações veiculadas pela mídia local e sítios na internet das próprias usinas e grupos.
} 
menos sete usinas sucroalccoleiras realizavam atividades produtivas no Triângulo Mineiro. $\mathrm{A}$ expansão recente ocorreu na transição do século, quando outros quatorze empreendimentos foram inaugurados, sobretudo na segunda metade da primeira década do século atual (dez novas usinas instaladas entre 2006 e 2010), contabilizando 21 unidades em funcionamento em 2010.

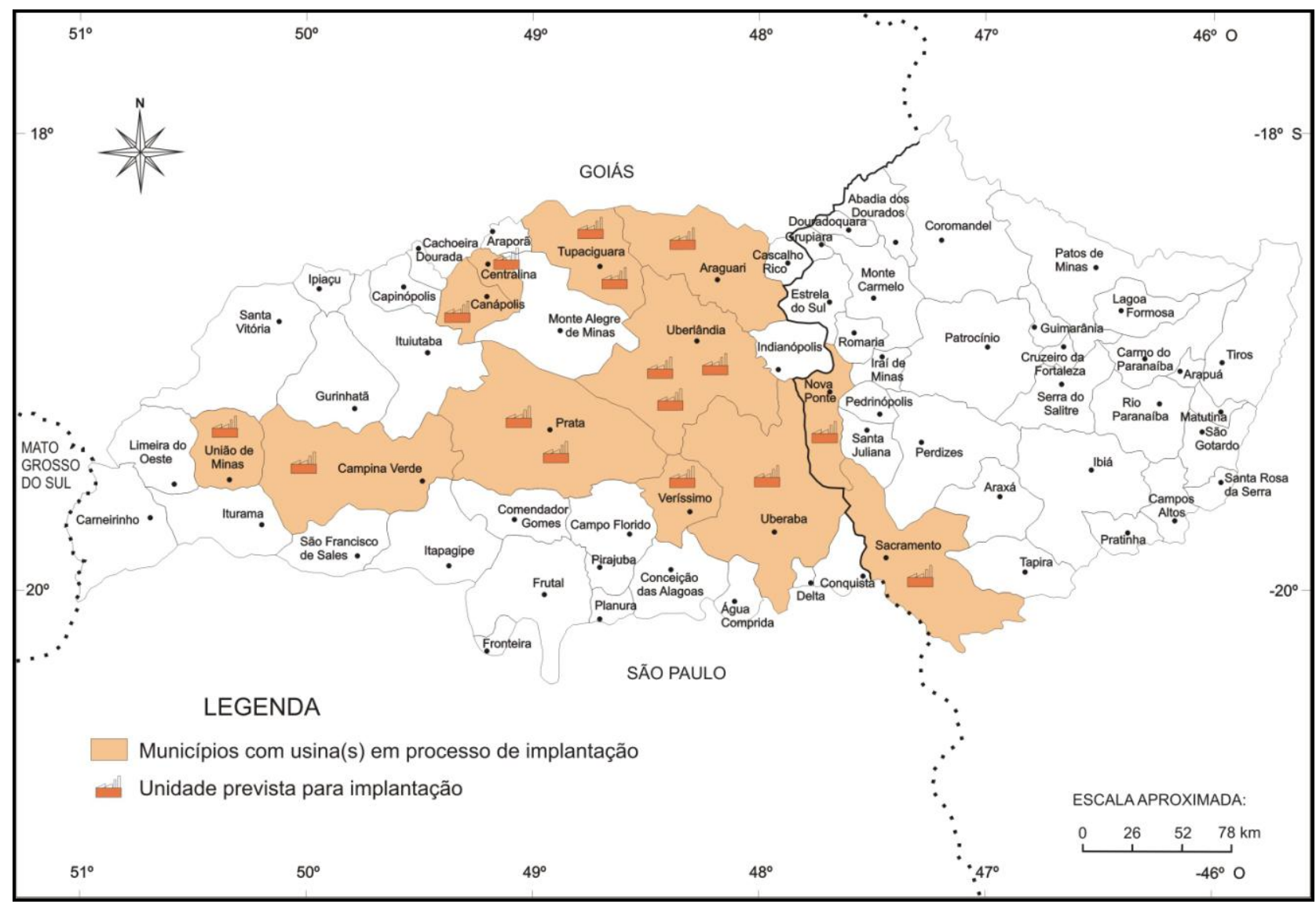

Figura 4. Usinas de açúcar/álcool em fase de implantação no Triângulo Mineiro/Alto Paranaíba (2010) Fonte: SIAMIG/SINDAÇÚCAR, 2010. Sítio dos grupos na internet. Org. do autor.

As crescentes demandas por etanol no mercado interno e externo, resultado de uma política global que valoriza os chamados "biocombustíveis" (como fonte renovável), o aumento da frota de veículos bi-combustível no país, e, mais recentemente, também o aumento da demanda pelo açúcar no mercado externo, promove a expansão dos investimentos e um aumento significativo no número de usinas sucroalcooleiras em todo o país.

Avaliando as implicações territoriais da expansão recente da cultura canavieira no território brasileiro, Ricardo Castillo (2009) aponta um conjunto de situações que, de alguma forma, também caracterizam a expansão recente da produção que ocorre no Triângulo Mineiro/Alto Paranaíba, como é o caso da substituição de culturas e ocupação de áreas de 
pastagens; a oligopolização do setor, com aquisições e fusões de grupos nacionais e estrangeiros (com centralização de capitais e desconcentração espacial da produção); a política agressiva de arrendamento de terras por parte das usinas (desestabilizando práticas pretéritas de pequenos produtores) e, por fim, um amplo conjunto de políticas públicas que viabiliza a expansão do parque de usinas (o que incluí crédito do BNDES, incentivos fiscais, investimentos em logística, etc.) (CASTILLO, 2009, p.2).

No que se refere à expansão territorial do cultivo, há claro esforço de ocupação, por parte dos novos grupos que investem na instalação de usinas, das áreas com melhor qualidade de solo e passíveis de mecanização (topografia plana). Isso tem ocorrido a partir da substituição de áreas antes ocupadas por cultivos temporários (inclusive com alguma competição em áreas antes cultivadas com milho/soja), mas principalmente pela substituição de áreas de pastagem. Intenso em técnica e envolvendo agentes qualificados para um trabalho diretamente ligado à ciência e tecnologia (emprego de defensivos, corretivos, máquinas modernas para a colheita, remuneração a partir de cálculo do teor de glicose nas plantas, etc.), o cultivo da cana de açúcar, da forma como tem atualmente se expandido na região, reforça o caráter da agricultura moderna e intensa em capital (Figura 5).

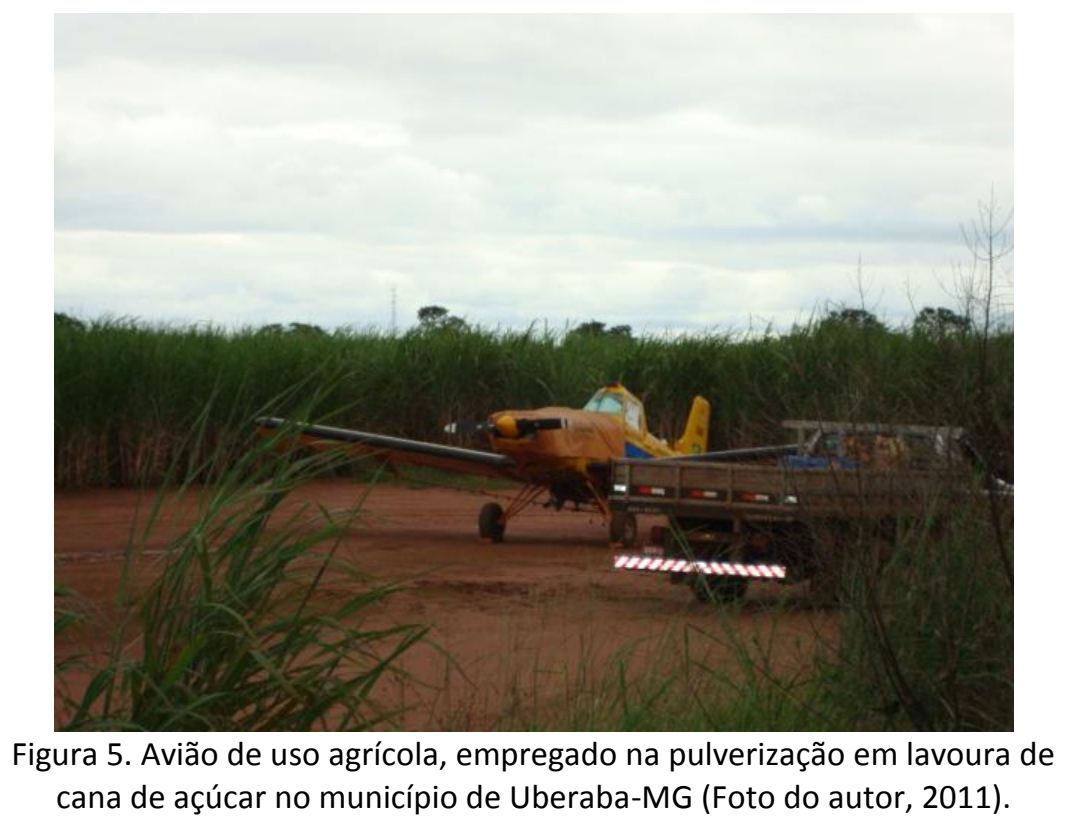

A expansão recente ocorre, marcadamente, pela inserção de grupos estrangeiros que, ora implantam novos empreendimentos, instalando diretamente novas unidades produtivas, ora adquirem plantas industriais de usinas que funcionavam de forma autônoma ou que eram 
coordenadas por grupos nacionais. Existe, assim, um conjunto diverso de investimentos no setor sucroalcooleiro na região (grupos nacionais/estrangeiros, usinas autônomas/grandes grupos econômicos), numa tendência que, a primeira vista, indica certa concentração de poder no campo, processo este já apontado por Cleps Jr. (2009), haja vista o poder de controle exercido por grandes grupos estrangeiros. O grupo Bunge, por exemplo, controla hoje as usinas de Itapagipe (adquirida através da compra do grupo Moema), Santa Juliana (adquirida do grupo Tenório, no ano de 2007) e também uma usina recém inaugurada no município de Frutal. A Louis Deyfrus Commodities (em parceria com o grupo Vale) instalou em 2009 uma unidade no município de Ituiutaba, mesmo ano em que o grupo estadunidense ADM (em parceria com o grupo nacional Cabrera) instalou uma usina no município de Limeira do Oeste.

Em tempos em que a corrida pelas fontes renováveis (agroenergia) e o discurso de sustentabilidade redefinem a geopolítica e as estratégias de produção de energia na escala do planeta, o setor sucroalcooleiro no Brasil, estratégico para o país e construído a duras penas através de investimentos vultosos do Estado (Pró-álcool, nos anos 1970 e 1980), é cada vez mais alvo de interesse de grupos estrangeiros. Tornando-se uma "commodity globalizada", com preços regulados internacionalmente e uma produção interna agora gerida também por grupos estrangeiros, o país perde a regulação sobre os preços do etanol e o aumento do volume de produção não tem assegurado maior poder de regulação no mercado internacional e nem mesmo garantido preço estável e regularidade de abastecimento para o mercado interno (PEREIRA, 2010, p.353).

O arrendamento das terras para a produção da cana de açúcar na região é outro motivo de preocupação e revela a situação de instabilidade do território (SANTOS, 1978; SANTOS; SILVEIRA, 2001; SILVEIRA, 2002). Se nas tradicionais regiões de cultivo no país (interior de São Paulo e Zona da Mata nordestina, etc.), ou mesmo na produção realizada no Triângulo Mineiro até os anos 1990, as terras eram adquiridas pelos usineiros, hoje cada vez mais ocorre um processo de "terceirização" do plantio da cana de açúcar, com a existência de contratos entre produtores e usinas ou, também de forma subordinada, o estabelecimento de contratos de arrendamento por longos períodos e com clara situação de dependência dos proprietários de terras em relação às usinas e grupos que controlam a produção de açúcar e álcool na região. 
A usina de Iturama, por exemplo, instalada no município desde 1994, produz cana-de-açúcar em terras dos seus próprios acionistas, bem como estabeleceu uma rede de parceiros que conta com cerca de uma centena de fornecedores localizados nas proximidades do empreendimento. Uma unidade produtiva instalada no município de Frutal nos informou a contratação, para a safra 2010/2011, de cerca de 23 mil hectares para o plantio da cana de açúcar, também distribuídos em cerca de uma centena de propriedades nos municípios de Frutal, Itapagipe, Comendador Gomes e Fronteira.

Tais práticas de contratação para o arrendamento são comuns hoje no Triângulo Mineiro/Alto Paranaíba e foram bem avaliadas por Faria (2011), particularmente no município de Ibiá, onde esquemas de subordinação de proprietários de terras garantem a viabilidade de uma usina em funcionamento desde 2004. Tais práticas de arrendamento de terras para o plantio da cana de açúcar ocorrem, inclusive, em áreas de assentamento para reforma agrária, produção esta destinada a uma usina localizada no município de Campo Florido, conforme avaliaram Souza e Cleps Jr. (2009, p.14).

Como o investimento para a instalação de novas usinas é alto, tais projetos contam com apoio de um conjunto de políticas públicas que viabilizam empréstimos e demais benfeitorias, inclusive para os maiores grupos externos que investem no setor. Práticas como as de doação de terrenos, isenção de impostos, etc. tornam-se comuns, instigando inclusive disputas acirradas entre municípios no que se refere à capacidade de atração de tais investimentos. A usina Vale do Tijuco (Companhia Mineira de Açúcar e Álcool), por exemplo, que integra investimentos de grupos nacionais e estadunidenses, investiu cerca de R\$ 300 milhões para a implantação de uma primeira unidade no Triângulo Mineiro (no município de Uberaba), com financiamentos do BNDES. A mesma usina e o governo do estado de Minas Gerais, realizam, em esquema de parceria público-privado (PPP), esforços para a pavimentação de rodovias que facilitarão o escoamento da produção em área onde a usina arrenda terras para o plantio. É todo um reordenamento das atividades e uma reconfiguração das materialidades do território, onde o poder dos novos empreendimentos é capaz de induzir políticas e a mobilização de capital público que, em última análise, viabilizam uma acumulação corporativa. 

agricultura e seu papel no desenvolvimento da região

Em que pese os problemas ambientais e sociais decorrentes da expansão da agricultura moderna, da forma como ela ocorre no Triângulo Mineiro/Alto Paranaíba, a região se tornou um espaço funcional e conveniente (SANTOS, 1994, p.98) para os interesses corporativos de grandes grupos e empresas, tanto no que diz respeito à produção de grãos, quanto, e cada vez mais, no que se refere à produção de cana-de-açúcar.

É inegável que a agricultura moderna realizada no Triângulo Mineiro/Alto Paranaíba tem contribuído para a modernização da região, para a sua inserção nos modernos circuitos produtivos e, desta forma, também para um adensamento do meio técnico-científico e para a sua definitiva participação no processo de globalização (PESSÔA, 2007, p.265), no entanto, é preciso pensarmos que os ganhos auferidos de fato não se distribuem de forma equitativa, nem no conjunto do território e menos ainda no conjunto da sociedade.

No que se refere particularmente à produção de grãos, a moderna agricultura hoje realizada na região acabou por concentrar, em alguns poucos pontos, o processamento e a industrialização do que é produzido no campo. Nesse sentido, os principais agentes que organizam a produção elegeram principalmente o município de Uberlândia como centro de processamento da produção agrícola. É por isso que a produção comandada por grupos como Cargill, ADM e Algar Agro converge para Uberlândia, onde os grãos são processados e de onde os derivados são posteriormente distribuídos.

Aparecendo como um "centro ganhador" e concentrador das benesses de uma economia que se realiza no campo moderno (centralizando os serviços especializados, as plantas industriais, etc.), Uberlândia torna-se o principal centro urbano regional, mas para além das infraestruturas modernas também concentra e reproduz problemas típicos da formação socioespacial brasileira, o que nos leva a compreender que, por si só, a economia do campo moderno $\mathrm{e}$ as atividades urbanas que lhe são complementares não garantem desenvolvimento e distribuição dos ganhos. Algumas evidências deste processo nos parecem elucidativas e merecem ser destacadas.

Intenso em técnica e capital, tal processo acaba por empregar uma mão-de-obra não muito numerosa, envolvendo muitas vezes trabalho temporário e terceirizado, o que não garante facilmente muitas oportunidades de renda para a maioria dos empregados no setor. A 
Cargill, por exemplo, que emprega cerca de 700 funcionários em sua planta industrial em Uberlândia (a maior unidade do grupo no Brasil e também a maior fora dos EUA), ampliou no ano de 2010 o setor de fabricação de amidos e adoçantes, aumentando em $70 \%$ sua capacidade produtiva. Foram investidos cerca de $\mathrm{R} \$ 112$ milhões na ampliação da fábrica e gerados 70 novos empregos diretos (CARGILL, 2010), ou seja, a criação de um novo posto de trabalho pelo grupo resulta de um investimento, em média, da ordem de $\mathrm{R} \$ 1,6$ milhão. Tal volume de capital, se aplicado no trabalho de pequenos empreendimentos no campo ou nas cidades ou ainda num trabalho direto de produção no campo, mas realizado em outros moldes, poderia render uma quantidade muito mais significativa de empregos, distribuindo renda.

No campo, a questão do trabalho e da geração de emprego parece ser ainda mais significativa. Ocupando principalmente áreas propícias à mecanização, a produção de gêneros como milho e soja destinados à comercialização realizada pelas tradings do agronegócio, ocorre muitas vezes em grandes propriedades onde imperam as práticas da monocultura, com plantio, manejo (adubação e aplicação de fertilizantes) e colheita, no mais das vezes, totalmente mecanizados. Exigente em capital e infraestruturas rígidas, tal agricultura, comandada por grandes grupos do setor, acaba ditando também uma estrutura fundiária concentrada. É assim que, no campo moderno, a presença intensa de capital, técnica e informação, em sua maior parte, é acompanhada de um trabalho humano pouco numeroso.

Um fato recente também evidencia esta situação de fragmentação e desarticulação social e territorial na região. Em maio de 2011, cerca de mil e duzentas famílias ocuparam uma área contígua à mancha urbana e que originalmente possuía mais de 1,5 milhão de metros quadrados (alvo de grilagem e parcelamentos irregulares). A ocupação foi coordenada pela Associação dos Trabalhadores Rurais Bela Vista, que desde 2009 ocupa áreas urbanas e rurais nas proximidades de Uberlândia (LEMOS, 2011). População muitas vezes oriunda do campo, tanto da região do Triângulo, como de outras partes do país, estes ocupantes não encontram condições de inserção digna na cidade, pois falta trabalho e quando estão ocupados desempenham funções pouco remuneradas e atividades precárias. Assim, a cidade "moderna" que cresce em meio a uma das regiões de agricultura mais dinâmica de Minas Gerais e do Brasil, é também uma cidade fragmentada e socialmente excludente, pois permanecem as desigualdades sociais. 
Os Agentes Do Agronegócio E O Uso Do Território No Triângulo Mineiro/Alto Paranaíba: Da Moderna Agricultura De Grãos À Expansão

RECENTE DA CANA De AÇúCAR

Mirlei Fachini Vicente Pereira

A tendência recente de expansão da cana-de-açúcar e da produção sucroalcooleira, mesmo que tenha (de modo desigual) inserido novas infraestruturas e dinamizado a economia local em pequenos núcleos urbanos, revela novamente um cenário em que a apropriação dos recursos gerados pelo trabalho moderno no campo não é distribuída de forma equitativa, não garantindo, portanto, melhorias nas condições materiais de vida da população mais pobre.

Em que pese a expansão de um cultivo moderno da cana de açúcar que, em grande parte, dispensa o emprego de grande quantidade de mão-de-obra (haja vista o emprego de máquinas modernas para a colheita), nos pequenos núcleos urbanos os migrantes arregimentados para o corte da cana de açúcar compõem um quadro significativo de empregados no campo que, em sua maioria, são urbano-residentes. Este é o caso de municípios como Delta, Campo Florido, Iturama, Araporã, entre outros, em que os migrantes nordestinos aparecem com importância no conjunto dos trabalhadores locais.

Num município como Delta, com cerca de 8 mil habitantes (2010) (onde se localiza a usina Caeté, uma das mais antigas instaladas na região), cujo pequeno núcleo urbano é visivelmente pobre e de infraestrutura escassa, pode-se observar grande quantidade de moradias adaptadas e precárias para abrigar trabalhadores do corte da cana de açúcar, bem como a organização e venda de passagens para viagens a várias localidades da região Nordeste, em ônibus fretados que partem de praças e bares (em geral um transporte clandestino e que não garante condições de segurança). O produto interno bruto (PIB) per capita do município é maior do que o de Uberlândia, mas o índice de pobreza do município, medido pelo IBGE em 2003, alcançava 31,81\%, um dos mais altos da região (IBGE Cidades, 2011). Assim, a arregimentação da mão-de-obra para o corte da cana de açúcar reproduz práticas já conhecidas no interior do estado de São Paulo - quando o emprego de mão-deobra (mesmo que sazonal) é intenso, paga-se pouco por uma atividade que expõe trabalhadores a uma série de riscos e que garante apenas uma remuneração injusta.

Deste modo, pode-se afirmar que, por si só, a agricultura moderna, muito intensa em capital, ciência e informação, mas realizada nos moldes ditados por grandes grupos que organizam os circuitos produtivos de commodities, segundo seus próprios interesses, não garante conquistas sociais para o conjunto da população, tanto nas maiores quanto nas menores cidades da região do Triângulo Mineiro/Alto Paranaíba. Faz-se necessário refletirmos sobre os esforços sociais e os investimentos públicos que garantem a viabilidade 
Os Agentes Do Agronegócio E O Uso Do Território No TriÂngulo MineIro/Alto Paranaíba: Da Moderna Agricultura De Grãos À Expansão

do agronegócio moderno no Brasil, que, privilegiando um conjunto seleto de macroatores da economia, torna residuais as preocupações voltadas para o conjunto da sociedade e do território.

\section{Agradecimento}

O autor agradece o auxílio financeiro da Fundação de Amparo à Pesquisa do Estado de Minas Gerais - FAPEMIG para a realização da pesquisa.

\section{REFERÊNCIAS BIBLIOGRÁFICAS}

BERNARDES, J. A. Agricultura moderna e novos espaços urbanos no cerrado brasileiro. In: XI Encuentro de Geógrafos de América Latina. Anais... Bogotá, 21p. 2007.

CARGILL. Cargill amplia fábrica de amidos e adoçantes em Uberlândia. Cargill Notícias 2010. Página do grupo Cargill na internet. Disponível em <http://www.cargill.com.br/brazil/pt/home/noticias/2010/NA3024749.jsp>, acesso em dezembro de 2010.

CASTILLO, R. Exportar alimentos é a saída para o Brasil? o caso do complexo da soja. In: ALBUQUERQUE, Edu Silvestre (org). Que país é esse? Pensando o Brasil contemporâneo. São Paulo: Globo. p.283-307. 2005.

Região competitiva e circuito espacial produtivo: a expansão do setor sucroalcooleiro no Brasil. VII Encontro Nacional da ANPEGE, Curitiba, 2009. Anais... Curitiba, 2009, $15 p$.

Agronegócio e logística em áreas de cerrado: expressão da agricultura científica globalizada. Revista da Anpege. V.3, p.33-43, 2007.

CLEPS, Jr. J. Concentração de poder no agronegócio e (des)territorialização: os impactos da expansão recente do capital sucroalcooleiro no Triângulo Mineiro. Caminhos de Geografia. Uberlândia, v. 10, n. 31, p. 249-264, 2009. 
COELHO, O. de M. Dinâmica territorial da agricultura moderna no Triângulo Mineiro: Uma avaliação do uso do território pelas grandes empresas do agronegócio. Relatório final de pesquisa - CNPq-UFU. Instituto de Geografia-UFU. Uberlândia, julho de 2011 (mimeo).

ELIAS, D. Globalização e fragmentação do espaço agrícola no Brasil. Scripta Nova. Revista de Geografía y Ciências Sociales. Barcelona, Vol. X, no218 (3), 19p. 2006.

FARIA, A. H. A expansão da cana-de-açúcar na mesorregião do Triângulo Mineiro/Alto Paranaíba (MG): o discurso da modernidade e as des(re)territorializações nos cerrados do município de Ibiá. Dissertação (Mestrado em Geografia), IG-UFU. Uberlândia, 2011.

FREDERICO, Samuel. O novo tempo do cerrado: expansão dos fronts agrícolas e controle do sistema de armazenamento de grãos. São Paulo: Annablume/Fapesp, 2010.

IBGE (Instituto Brasileiro de Geografia e Estatística). IBGE Cidades. Disponível em http://www.ibge.gov.br/cidadesat/topwindow.htm?1, vários acessos em 2010 e 2011.

LEMOS, Vinícius. Área urbana foi invadida por 1,2 mil pessoas. Correio de Uberlândia (Jornal). 14 de maio de 2011. Disponível em: http://www.correiodeuberlandia.com.br/cidade-e-regiao/area-urbana-foi-invadida-ha-umasemana-por-12-mil-pessoas/, acesso em julho de 2011.

NEDER, H. D.; CLEPS Jr, J. Agroindústria e sustentabilidade. In: SHIKI, S.; GRAZIANO DA SILVA, J.; ORTEGA, A. C. (org.). Agricultura, meio ambiente e sustentabilidade do cerrado brasileiro. Uberlândia: UFU, 1997. p.199-224.

MINAS GERAIS (Estado). Perfil do Agronegócio 2003-2009. Secretaria de Agricultura e Abastecimento de Minas Gerais. Belo Horizonte, 2010.

PEREIRA, M. F. V. A inserção subordinada do Brasil na divisão internacional do trabalho: conseqüências territoriais e perspectivas em tempos de globalização. Sociedade \& Natureza. Uberlândia, vol. 22, n.2, p.347-355, 2010. Disponível em <http://www.scielo.br/scielo.php?script=sci_arttext\&pid=S198245132010000200009\&lng=en\&nrm=iso>, acesso em novembro de 2010. 
Os Agentes Do Agronegócio E O Uso Do Território No TriÂngulo MineIro/Alto Paranaíba: Da Moderna Agricultura De Grãos À Expansão RECENTE DA CANA DE AÇÚCAR

Mirlei Fachini Vicente Pereira

PESSÔA, V. L. S. Meio técnico-científico-informacional e modernização da agricultura: uma reflexão sobre as transformações no cerrado mineiro. In: MARAFON, G. J.; RUA, J.; RIBEIRO, M. A. (org.) Abordagens teórico-metodológicas em geografia agrária. Rio de Janeiro: Eduerj, 2007. P.255-269.

SANTOS, M. O trabalho do geógrafo no Terceiro Mundo. São Paulo: Hucitec, 1978.

Técnica, espaço e tempo: globalização e meio técnico-científico-informacional. São Paulo: Hucitec, 1994.

Por uma outra globalização. Do pensamento único à consciência universal. Rio de Janeiro: Record, 2000.

SANTOS, M.; SILVEIRA, M. L. O Brasil: território e sociedade no início do século XXI. Rio de Janeiro: Record, 2001.

SIAMIG/SINDAÇÚCAR. Associação das indústrias sucroenergéticas de Minas Gerais (sítio na internet). Disponível em http://www.siamig.org.br/, vários acessos em 2010.

SILVEIRA, M. L. Uma globalização desnecessária, um território instável. Ciência Geográfica. Bauru, vol.1, n.21, p.43-46, 2002.

SOUZA, A. G.; CLEPS Jr., J. O desenvolvimento da agroindústria canavieira no Triângulo Mineiro e seus impactos sobre a mão-de-obra e a produção de alimentos. XIX ENCONTRO NACIONAL DE GEOGRAFIA AGRÁRIA, São Paulo, 2009. Anais... São Paulo, 2009, 16p.

Artigo recebido em 09/03/2012.

Artigo aceito em 12/04/2012. 